\title{
Studi Perencanaan Koordinasi Proteksi Mempertimbangkan Busur Api pada Sistem Kelistrikan PT. Semen Indonesia Aceh Menggunakan Standar IEEE 1584-2002
}

\author{
Dhimas Oktavian Andryana, Ontoseno Penangsang, Rony Seto Wibowo \\ Jurusan Teknik Elektro, Fakultas Teknologi Industri, Institut Teknologi Sepuluh Nopember (ITS) \\ Jl. Arief Rahman Hakim, Surabaya 60111 \\ e-mail:ontosenop@ee.its.ac.id, ronyseto@ee.its.ac.id
}

\begin{abstract}
Abstrak -PT. Semen Indonesia pabrik Aceh merupakan perusahaan patungan (joint venture company) antara PT. Semen Indonesia (Persero) bersama PT. Samana Citra Agung. Total daya listrik yang dibutuhkan sebesar 85.8 MW dengan sistem kelistrikan pada sistem tegangan rendah dan menengah. Guna menjaga kontinuitas daya listrik, diperlukan koordinasi proteksi untuk meminimalisir dampak yang ditimbulkan ketika terjadi gangguan. Salah satu dampak yang ditimbulkan adalah adanya busur api (arc flash). Namun demikian, energi yang dihasilkan oleh busur api setelah dilakukan koordinasi proteksi perlu dipertimbangkan agar tidak melampaui standard yang diizinkan. Analisa busur api dilakukan dengan menggunakan perhitungan standar IEEE 1584-2002. Setelah dilakukan beberapa analisa didapatkan bahwa beberapa daerah di PT. Semen Indonesia pabrik Aceh memiliki nilai insiden energi diatas kategori 4, sehingga diperlukan tambahan peralatan berupa rele differensial sebagai pengaman utama agar nilai insiden energi busur api bisa dikategorikan sesuai standard NFPA 70E.
\end{abstract}

Kata Kunci-IEEE 1584-2002, Insiden Energi, Koordinasi Proteksi, NFPA 70E, PT. Semen Indonesia Aceh.

\section{PENDAHULUAN}

$\mathrm{P}^{\mathrm{T}}$ T. Semen Indonesia Aceh merupakan perusahaan patungan (joint venture company) antara PT. Semen Indonesia (Persero) bersama PT. Samana Citra Agung. Total daya listrik yang dibutuhkan sebesar 85.8 MW dengan sistem kelistrikan pada sistem tegangan rendah dan menengah. Guna menjaga kontinuitas daya listrik, diperlukan koordinasi proteksi untuk meminimalisir dampak yang ditimbulkan ketika terjadi gangguan. Salah satu dampak yang ditimbulkan adalah adanya busur api (arc flash). Oleh sesab itu, demi menjaga keamanan dan keselamatan pekerja dari bahaya arc flash perlu diketahui energi yang dihasilkan.Besar energi busur api tidak boleh melebihi standard yang diizinkan karena dapat membahayakan keselamatan pekerja.

Berdasarkan standar IEEE 1584-2002 yang berkaitan tentang masalah arc flash, analisa bahaya arc flash harus dilakukan dengan melakukan studi terhadap kordinasi proteksi dan hubung singkat. Studi proteksi diperlukan untuk menentukan waktu peralatan proteksi dalam mengisolasi ketika terjadi hubung singkat. Sedangkan studi hubung singkat digunakan untuk mendapatkan nilai arus bolted gangguan tiga fasa. Tetapi pada standar ini tidak dipertimbangkan berkurangnya kontribusi arus hubung singkat pada tiap satuan waktu, dan waktu pemutusan masingmasing CB (Circuit Breaker) dalam melokalisir gangguan.

Dengan hasil analisa insiden energi arc flash yang diperoleh, akan digunakan untuk menentukan batasan jarak dari titik yang berpotensi terjadi arc flash dengan pekerja dan akan ditentukan kategori bahaya arc flash beserta jenis alat pelindung diri sesuai dengan standar NFPA 70E yang dipakai oleh pekerja.

\section{II.URAIAN PENELITIAN}

\section{A. Definisi Busur Api Listrik}

Menurut National Fire Protection Association (NFPA) 70E-2004, arc flash adalah kondisi yang berbahaya akibat adanya pelepasan energi yang disebabkan oleh bunga api listrik [1]. Bunga api listrik timbul karena adanya arus gangguan atau disebut arcing fault pada sebuah sistem kelistrikan. Penyebab arus gangguan sangat bermacammacam antara lain, kegagalan isolasi, kegagalan mekanik, debu, korosi, atau kesalahan pekerja yang bekerja pada sistem kelistrikan. National Fire Protection Association (NFPA) 70E-2004, arc flash adalah kondisi yang berbahaya akibat adanya pelepasan energi yang disebabkan oleh bunga api listrik [1]. Bunga api listrik timbul karena adanya arus gangguan atau disebut arcing fault pada sebuah sistem kelistrikan. Penyebab arus gangguan sangat bermacammacam antara lain, kegagalan isolasi, kegagalan mekanik, debu, korosi, atau kesalahan pekerja yang bekerja pada sistem kelistrikan.

Saat insiden energi arc flash maka akan muncul pembakaran dari busur api. Efek yang dihasilkan arc flash dapat berupa ledakan, radiasi panas, cahaya yang menyilaukan, dan tekanan yang sangat besar. Temperatur dari radiasi panas yang dihasilkan dapat mencapai sekitar $35.000^{\circ} \mathrm{F}$, atau sekitar empat kali panas permukaan matahari. Temperatur yang tinggi juga merubah keadaan konduktor dari padat ke logam cair panas dan uap. Hal tersebut sangat 
berbahaya Karena dapat menyebabkan kerusakan pada perlatan listrik dan kecelakaan fatal pada pekerja. Oleh karena itu level busur api harus diminimalkan sesuai standar NFPA 70E. Gambar 1 menunjukkan efek yang ditimbulkan oleh arc fault.

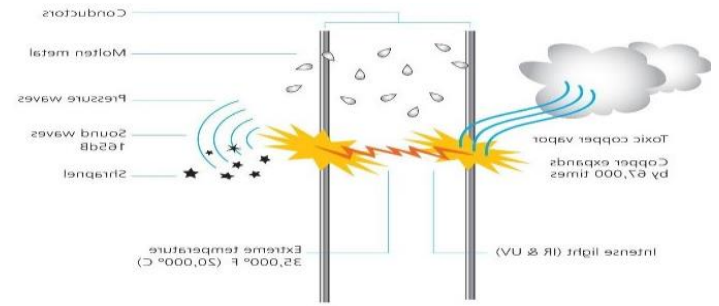

Gambar 1. Efek arc Flash.

B. Perhitungan Insiden Energi Busur Api dengan Standar IEEE 1584-2002

Berdasarkan standar IEEE 1584-2002, perhitungan arcing current merupakan langkah awal dalam perhitungan level energi arc flash. Nilai arcing current diperoleh berdasarkan arus hubung singkat tiga fasa. Berikut adalah persamaan untuk perhitungan arcing current pada sistem tegangan dibawah $1000 \mathrm{~V}$.

$\lg \mathrm{Ia}=\mathrm{K}+0.662 \lg \mathrm{I}_{\mathrm{bf}}+0.0966 \mathrm{~V}+0.000526 \mathrm{G}+0.5588$ $\mathrm{V}\left(\lg \mathrm{I}_{\mathrm{bf}}\right) 0.00304 \mathrm{G}\left(\lg \mathrm{I}_{\mathrm{bf}}\right)$

Keterangan :

$$
\begin{array}{ll}
\mathrm{lg} & : \log _{10} \\
\mathrm{Ia} & : \text { arus } \operatorname{arcing}(\mathrm{kA}) \\
\mathrm{V} & : \text { tegangan sistem }(\mathrm{kV}) \\
\mathrm{G} & : \text { jarak antar konduktor }(\mathrm{mm}) \\
\mathrm{K} & :-0.153 \text { untuk konfigurasi terbuka dan }-0.097 \\
& \text { untuk konfigurasi box } \\
\mathrm{I}_{\mathrm{bf}} & \text { : bolted fault current pada gangguan tiga fasa } \\
& \text { (symmetrical } R M S)(\mathrm{kA})
\end{array}
$$

Sedangkan pada sistem tegangan lebih dari $1000 \mathrm{~V}$ menggunakan persamaan berikut [2].

$\lg \mathrm{Ia}=0.00402+0.983 \lg \mathrm{I}_{\mathrm{bf}}$

Dari persamaan (2) dapat dijabarkan menjadi : $\lg I a-0,983 \lg I b f=0,00402$

$\lg I a-\lg I b f^{0,983}=0,00402$

$\lg \left(\frac{I a}{I b f^{0,983}}\right)=0,00402$

$\frac{I a}{I b f^{0,983}}=10^{0,00402}$

$\frac{I a}{I b f^{0,983}}=1,00929$

$I a=1,00929 I b f^{0,983}$

Menurut standar IEEE 1584-2002, perhitungan nilai insiden energi arc flash menggunakan persamaan sebagai berikut. Pertama digunakan $\log _{10}$ normalized. Persamaan tersebut berdasarkan data normalized waktu arcing yaitu 0.2 detik dan jarak dari titik arcing ke pekerja yaitu $610 \mathrm{~mm}$. Secara keseluruhan persamaannya sebagai berikut.

$\operatorname{Ig~En}=\mathrm{K} 1+\mathrm{K} 2+1.081 \mathrm{Ig} \mathrm{Ia}+0.0011 \mathrm{G}$
$E n=I a^{1,081} 10^{\left(K_{1}+K_{2}+0,0011 G\right)}$

Keterangan :

En : insiden energi $(\mathrm{J} / \mathrm{cm})$ normalized untuk waktu dan jarak

K1 : -0.792 untuk konfigurasi terbuka (no enclosure) dan

-0.555 untuk konfigurasi box (enclosure equipment)

K2 : 0 untuk sistem ungrounded and highresistance grounded dan -0.113 untuk sistem grounded

G : gap antara konduktor (mm)

Adanya variabel waktu , $(x)$ faktor dan jarak antara peralatan dengan pekerja maka akan menghasilkan jumlah energi yang dilepaskan ke udara. Besarnya insiden energi dapat dituliskan dalam persamaan berikut:

$$
E=4,184 C f E n\left(\frac{t}{0,2}\right)\left(\frac{610}{D}\right)^{x}
$$

dimana,

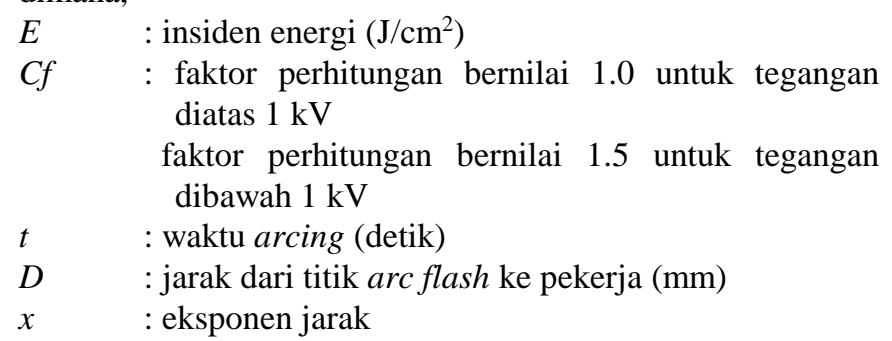

\section{Perhitungan Flash Protection Boundary}

Flash protection boundary adalah batas jarak perlindungan terhadap titik arc flash. Flash protection boundary merupakan jarak tertentu konduktor aktif yang memungkinkan seseorang terkena bahaya arc flash (arc flash hazard), sedangkan jarak ini dapat dikategorikan setelah nilai insiden energi arc flash diketahui.

Dalam menentukan batasan perlindungan arc flash, diperlukan suatu perhitungan agar mengetahui batasan aman bagi pekerja terhadap peralatan bertegangan. Berikut persamaannya sesuai standar IEEE 1584-2002 [2]. Untuk level tegangan $<15 \mathrm{kv}$ menggunakan persamaan sebagai berikut.

$D_{B}=\left[4,184 C f \operatorname{En}\left(\frac{t}{0,2}\right)\left(\frac{610^{x}}{E_{B}}\right)\right]^{\frac{1}{x}}$

Keterangan :

$D_{B} \quad$ : jarak batas dari titik arcing $(\mathrm{mm})$

$C_{f} \quad$ : faktor pengali 1.0 untuk tegangan diatas $1 \mathrm{kV}$ dan 1.5 untuk tegangan dibawah $1 \mathrm{kV}$

$E_{n} \quad$ : incident energy normalized

$E_{B} \quad$ : incident energy in $\mathrm{J} / \mathrm{cm}^{2}$ at the boundary distance

$t \quad$ : waktu arcing (detik)

$x \quad$ : jarak exponent

Ibf : bolted fault current

$E_{B} \quad: 5.0 \mathrm{~J} / \mathrm{cm}^{2}$ untuk bare skin (no hood) atau rating dari PPE yang diajukan $\left(5.0 \mathrm{~J} / \mathrm{cm}^{2}=1.2 \mathrm{cal} / \mathrm{cm}^{2}\right)$ 
E. Pengelompokkan Kategori Insiden Energi Arc Flash dengan Perlengkapan Keselamatan Diri sesuai Standart NFPA $70 E$

Pengelompokan kategori energi busur api dapat ditentukan setelah mendapatkan nilai insiden energi pada masing-masing bus. Pengelompokan kategori tersebut bertujuan untuk menentukan alat pelindung diri untuk pekerja yang sesui personal protection equipment (PPE) dengan standar NFPA 70E.

Tabel 1.

Kategori Alat Pelindung Diri.

\begin{tabular}{|ccc|} 
Kategori & $\begin{array}{c}\text { Level Energi } \\
\left(\mathrm{Cal} / \mathrm{cm}^{2}\right)\end{array}$ & PPE - PPC yang Dibutuhkan \\
\hline 0 & $<2$ & $\begin{array}{c}\text { Bahan yang tidak meleleh, mudah terbakar } \\
\text { (Contoh : kain katun, wol, sutra, atau } \\
\text { campuran bahan - bahan tersebut) }\end{array}$ \\
\hline 1 & $2-4$ & Pakaian dan celana yang tahan api \\
\hline 2 & $4-8$ & $\begin{array}{c}\text { Pakaian dalam dengan kain katun, serta } \\
\text { pakaian luar dan celana yang tahan api }\end{array}$ \\
\hline 3 & $8-25$ & $\begin{array}{c}\text { Pakaian dalam kain katun ditambah baju } \\
\text { dan celana yang tahan api ditambah pakaian } \\
\text { tahan api yang mencakup seluruh tubuh }\end{array}$ \\
\hline 4 & $25-40$ & $\begin{array}{c}\text { Pakaian dalam katun ditambah baju dan } \\
\text { celana tahan api ditambah mantel dan } \\
\text { celana tahan api double layer }\end{array}$ \\
\hline
\end{tabular}

\section{F. Rele Arus Lebih (Overcurrent Relay)}

Rele arus lebih adalah rele pengaman yang bekerja terhadap arus lebih. Rele akan bekerja bila arus yang mengalir melebihi nilai settingnya (Iset). Rele arus lebih memiliki dua jenis yaitu rele arus lebih waktu (time overcurrent) dan rele arus lebih sesaat (instantaneous). Time overcurrent relays bekerja dengan delay waktu yang bergantung pada arus yang melalui rele, sedangkan instantaneous relays bekerja tanpa delay waktu yang disengaja dan digunakan untuk pengaman gangguan yang berada di dekat sumber ketika arus gangguan tinggi. Dalam mengatur rele arus lebih harus diperhatikan batasan besarnya arus dimana rele tidak boleh bekerja pada saat beban maksimum. Berdasarkan British BS 142-1983, batas pengaturan dalam rentang nominal 1.05-1.3 Iset. Berikut persamaan setting rele[3].

$$
\begin{aligned}
& I_{\text {set }}=\geq 1.05 \times I_{\text {nominal }} \\
& I_{s}=\frac{I_{s s t}}{C T_{\text {ratio }}} \\
& T_{\text {ap }}=I_{s} / I_{n} \\
& I_{\text {get }}=\operatorname{tap} \times I_{n} \times C T
\end{aligned}
$$

Batasan maksimum juga harus diperhatikan dalam pengaturan rele arus lebih. Persamaan pengaturan batasan maksimum penyetelan adalah sebagai berikut [3].

$$
\begin{aligned}
& I_{\text {set }} \leq 0.8 I_{\text {scmin }} \\
& T \text { ap }=\frac{I_{\text {sat }}}{C T_{\text {primary }}}
\end{aligned}
$$

Keterangan :

$$
\begin{array}{ll}
\text { Iset } & \text { : arus pickup (ampere) } \\
\text { Is } & \text { : arus setting (ampere) }
\end{array}
$$

Waktu operasi rele ditentukan dalam pengaturan time dial. Time dial menunjukkan kecuraman dari kurva rele.
Persamaan yang digunakan untuk menentukan time dial dari masing-masing kurva karakteristik adalah sebagai berikut [3].

$$
\begin{aligned}
& \mathrm{Td}=\frac{\mathrm{t} .\left[\left[\frac{1 \cos \max }{\operatorname{Iget}}\right)^{\mathrm{m}}-1\right]}{\mathrm{k}} \\
& \text { Keterangan : } \\
& \mathrm{t} \quad \text { : waktu operasi (detik) } \\
& \text { Td : time dial } \\
& \text { I : nilai arus (ampere) } \\
& \text { Iset : arus pickup (ampere) } \\
& \mathrm{k} \quad \text { : koefisien invers } 1 \\
& \alpha \quad \text { :koefisien invers } 2 \\
& \beta \quad \text { : koefisien invers } 3
\end{aligned}
$$

Tabel 2.

Koefisien Invers Time Dial [3].

\begin{tabular}{llll}
\hline \multicolumn{1}{c}{ Tipe Kurva } & \multicolumn{3}{c}{ Koefisien } \\
& \multicolumn{1}{c}{ K } & \multicolumn{1}{c}{$\boldsymbol{\alpha}$} & \multicolumn{1}{c}{ B } \\
\hline Standard/Normal Inverse & 0.14 & 0.02 & 2.97 \\
Very Inverse & 13.50 & 1.00 & 1.5 \\
Extremely Inverse & 80.00 & 2.00 & 13.3 \\
\hline \hline
\end{tabular}

\section{SISTEM KELISTRIKAN}

Sistem kelistrikan pada PT. Semen Indonesia Aceh dirancang untuk memenuhi operasional perusahaan yang memanfaatkan energi listrik. Energi listrik tersebut digunakan sebagai operasional mesin pada pabrik dan operasional lainnya. Untuk itu diperlukan sistem kelistrikan yang handal agar kontinuitas operasional perusahaan tetap beroperasi. Salah satu cara untuk menjaga kontinuitas pelayanan listrik yaitu dengan cara meminimalisir gangguan hubung singkat. Gangguan hubung singkat tersebut dapat menimbulkan arc flash, sehingga diperlukan analisa sistem kelistrikan pada PT. Semen Indonesia pabrik Aceh.

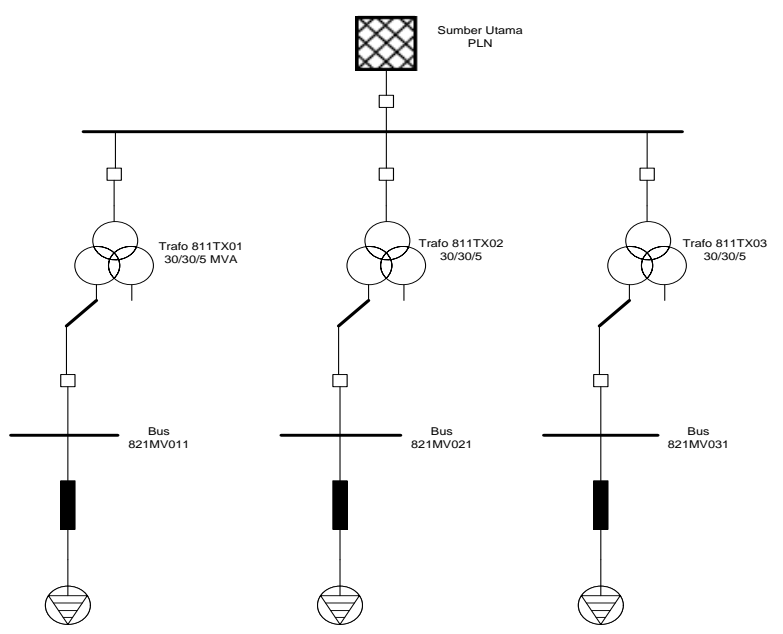

Gambar 2. Sistem Kelistrikan Semen Indonesia Aceh.

\section{SIMULASI DAN ANALISIS}

A. Hasil Simulasi Insiden Energi Arc Flash Menggunakan Perangkat Lunak ETAP 12.6.0 (Existing)

Simulasi insiden energi busur api (arc flash) menggunakan perangkat lunak ETAP 12.6.0 dengan perhitungan berdasarkan standar IEEE 1584-2002. Simulasi 
dilakukan pada level tegangan menengah $6.3 \mathrm{kV}$ di PT. Semen Indonesia Aceh. Pada bagian ini akan ditampilkan kondisi koordinasi proteksi existing. Data yang diambil contoh yaitu pada tipikal 1. Hasil nilai insiden energi pada tipikal 1 dapat dilihat pada table 3 .

Tabel 3.

Hasil Simulasi Insiden Energi Bus Tipikal 1.

\begin{tabular}{|c|c|c|c|c|c|}
\hline Bus ID & $\begin{array}{c}\text { Arus } \\
\text { Arcing } \\
(\mathbf{k A})\end{array}$ & $\begin{array}{c}\text { FCT } \\
(\mathrm{s})\end{array}$ & $\begin{array}{c}\text { Insiden } \\
\text { Energi } \\
\left(\mathrm{cal} / \mathrm{cm}^{2}\right)\end{array}$ & $\begin{array}{c}\text { AFB } \\
(\mathbf{m})\end{array}$ & $\begin{array}{c}\text { Kategori } \\
\text { Bahaya } \\
\text { Busur } \\
\text { Api } \\
\end{array}$ \\
\hline 821MV011 & 27.521 & 0.8 & 39.87 & 33.5 & Level 4 \\
\hline 831MV041 & 18.726 & 0.56 & 18.41 & 15.1 & Level 3 \\
\hline Bus30 & 28.005 & 1.94 & 98.54 & 84.8 & > Level 4 \\
\hline $\begin{array}{l}\text { BUS- } \\
\text { 341FN03M01 }\end{array}$ & 17.91 & 0.4 & 12.53 & 10.2 & Level 3 \\
\hline
\end{tabular}

Besar insiden energi berkaitan dengan koordinasi proteksi dan waktu pemutusan $\mathrm{CB}$ terhadap melokalisir gangguan. Untuk itu akan dilihat kurva TCC rele pada tipikal 1 yang mewakili bus-bus pada table 5. Tipikal 1 merupakan koordinasi sistem pengaman dari sekunder trafo 3 belitan ID 811TX01 dengan rating 30/30/5 MVA sampai dengan beban motor induksi ID 341FN02M01. dengan daya $7100 \mathrm{~kW}$. Koordinasi rele tipikal 1 merupakan jalur dengan beban motor terbesar. Jalur ini melalui 4 rele, yaitu : rele 831MV041-CB6, rele 831MV041-CB5, rele 821MV011CB6, rele 821MV011-CB5. Single line diagram untuk tipikal 1 dapat dilihat pada gambar 3 .

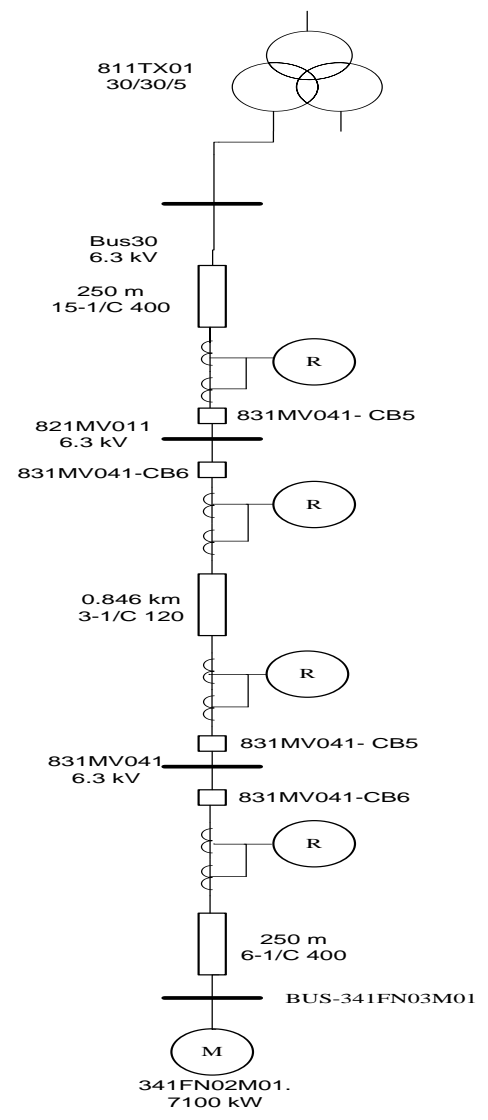

Gambar 3. Single Line Diagram Koordinasi Tipikal 1.
Dari hasil plot kurva TCC existing tipikal 1, dapat dilihat bahwa masih terjadi beberapa kordinasi yang kurang tepat.

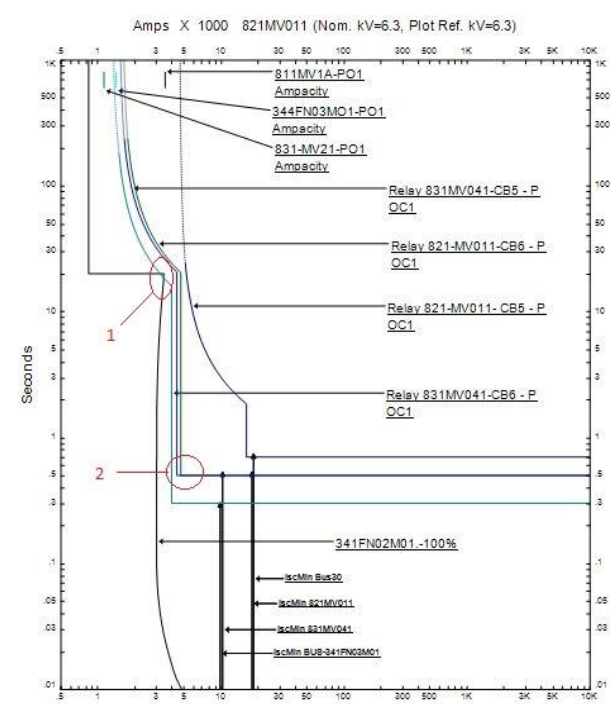

Gambar 4. Plot Kurva TCC Existing Tipikal 1.

Koordinasi yang kurang tepat pada plot kurva TCC gambar 4 diberi tanda lingkaran merah. Untuk tanda lingkaran merah nomor 1, bahwa kurva invers rele 831MV041-CB6 masih menyentuh kurva starting motor, sehingga motor tidak akan bisa start, sedangkan untuk tanda lingkaran merah nomor 2, bahwa rele 831MV041-CB5 dan rele 821MV011-CB6 memiliki waktu delay yang sama, sehingga ketika terjadi gangguan maka kedua rele tersebut bekerja secara bersamaan.

\section{B. Hasil Simulasi Insiden Energi Arc Flash Menggunakan Perangkat Lunak ETAP 12.6.0 (Existing)}

Dengan menggunakan persamaan (17), (18), dan (19) maka, dapat dilakukan resetting koordinasi proteksi terhadap tipikal 1.

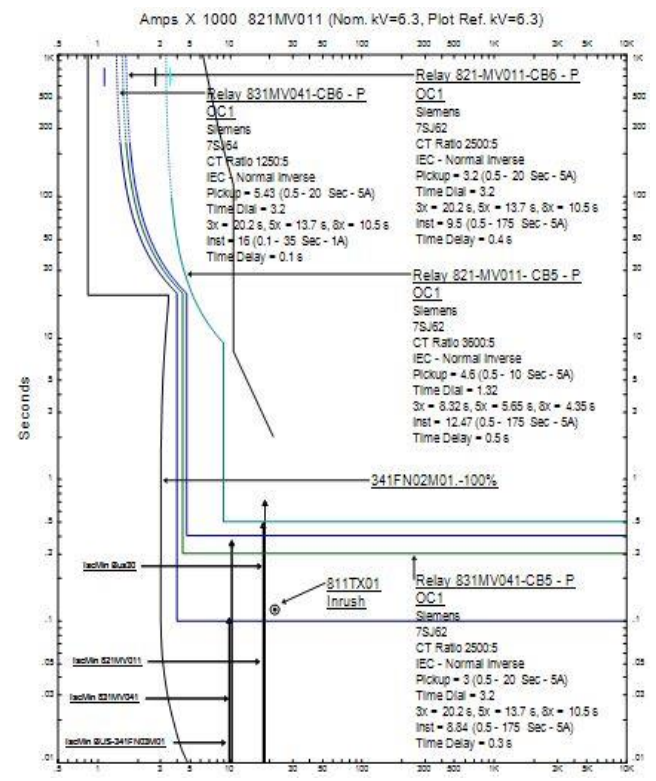

Gambar 5. Plot Kurva TCC Resetting Tipikal 1 
Dengan hasil perhitungan pada resetting tipikal 1 diatas didapatkan plot kurva TCC seperti pada gambar 5. Untuk hasil resetting dapat dilihat bahwa kurva invers rele 831MV041-CB6 sudah tidak lagi memotong kurva starting motor. Selain itu grading time antar rele 831MV041-CB5 dan rele 821MV011-CB6 sudah berbeda sehingga rele tidak akan bekerja bersamaan.

Tabel 4.

Hasil Simulasi Insiden Energi Bus Tipikal 1.

\begin{tabular}{lrrrrr}
\hline \hline Bus ID & $\begin{array}{c}\text { Arus } \\
\text { Arcing } \\
(\mathbf{k A})\end{array}$ & \multicolumn{1}{c|}{$\begin{array}{c}\text { FCT } \\
(\mathbf{s})\end{array}$} & $\begin{array}{c}\text { Insiden } \\
\text { Energi } \\
\left(\mathbf{c a l} / \mathbf{c m}^{2}\right)\end{array}$ & $\begin{array}{c}\text { AFB } \\
(\mathbf{m})\end{array}$ & $\begin{array}{c}\text { Kategori } \\
\text { Bahaya } \\
\text { Busur } \\
\text { Api }\end{array}$ \\
\hline 821MV011 & 27.521 & 0.6 & 29.9 & 24.9 & Level 4 \\
831MV041 & 18.726 & 0.4 & 13.15 & 10.7 & Level 3 \\
Bus30 & 28.005 & 1.94 & 98.54 & 84.8 & $>$ Level 4 \\
BUS- & 17.91 & 0.2 & 6.26 & 5 & Level 2 \\
341FN03M01 & & & & & \\
\hline \hline
\end{tabular}

C. Perhitungan Energi Busur Api (Resetting) dengan Standar IEEE 1584-2002

Untuk perhitungan menggunakan standar IEEE 15842002, dengan tegangan sistem $6,3 \mathrm{kV}$ untuk switchgear ungrounded system pada sistem kelistrikan PT. Semen Indonesia pabrik Aceh $\left(C f=1,0 ; K_{l}=-0,555 ; K_{2}=0 ; G=\right.$ $153 \mathrm{~mm} ; x=0,973$. Dengan menggunakan persamaan (8), (10), dan (11) maka, dapat ditentukan besarnya nilai insiden energi sebagai berikut :

$>\quad$ Perhitungan Insiden Energi Bus 821MV011 :

$\lg \mathrm{En}=\mathrm{K} 1+\mathrm{K} 2+1,081 \cdot \lg \mathrm{Ia}+0,0011 . \mathrm{G}$

$\lg$ En $=-0,555+0+1,081 \cdot \lg (27,521)+0,0011.153$

$\lg \mathrm{En}=-0,555+1,556+0,1683$

$\lg \mathrm{En}=1,1693$

$\mathrm{En}=10^{\lg \mathrm{En}}$

$\mathrm{En}=14,767 \mathrm{~J} / \mathrm{cm}^{2}$

$\mathrm{E}=4,184 . \mathrm{Cf} \cdot \mathrm{En} \cdot\left(\frac{t}{0,2}\right) \cdot\left(\frac{610^{x}}{D^{x}}\right)$

$\mathrm{E}=4,184 \cdot 1 \cdot 14,767 \cdot\left(\frac{0,6}{0,2}\right) \cdot\left(\frac{610^{0,273}}{914,4^{0,973}}\right)$

$\mathrm{E}=4,184.14,767 \cdot 3 \cdot 0,675$

$\mathrm{E}=125,115 \mathrm{~J} / \mathrm{cm}^{2}$

$\mathrm{E}=125,115 \mathrm{~J} / \mathrm{cm}^{2} \cdot 0,24=30,03 \mathrm{cal} / \mathrm{cm}^{2}$

$>$ Perhitungan Insiden Energi Bus 831MV041 :

$\lg \mathrm{En}=\mathrm{K} 1+\mathrm{K} 2+1,081 \cdot \operatorname{lgIa}+0,0011 . \mathrm{G}$

$\lg E n=-0,555+0+1,081 \cdot \lg (18,726)+0,0011.153$

$\lg \mathrm{En}=-0,555+1,376+0,1683$

$\lg \mathrm{En}=0,989$

$\mathrm{En}=10^{\lg \mathrm{En}}$

$\mathrm{En}=9,75 \mathrm{~J} / \mathrm{cm}^{2}$

$\mathrm{E}=4,184 . \mathrm{Cf} \cdot \mathrm{En} \cdot\left(\frac{\mathrm{t}}{0,2}\right) \cdot\left(\frac{610^{x}}{D^{x}}\right)$

$\mathrm{E}=4,184 \cdot 1 \cdot 9,75 \cdot\left(\frac{0,4}{0,2}\right) \cdot\left(\frac{610^{0,273}}{914,4^{0,273}}\right)$

$\mathrm{E}=4,184.9,75.2 \cdot 0,675$

$\mathrm{E}=55,072 \mathrm{~J} / \mathrm{cm}^{2}$

$\mathrm{E}=55,072 \mathrm{~J} / \mathrm{cm}^{2} \cdot 0,24=13,22 \mathrm{cal} / \mathrm{cm}^{2}$
$>$ Perhitungan Insiden Energi Bus Bus30:

$\lg \mathrm{En}=\mathrm{K} 1+\mathrm{K} 2+1,081 \cdot \operatorname{lgIa}+0,0011 \cdot \mathrm{G}$

$\lg \mathrm{En}=-0,555+0+1,081 \cdot \lg (28,005)+0,0011.153$

$\lg \mathrm{En}=-0,555+1,564+0,1683$

$\lg \mathrm{En}=1,178$

$\mathrm{En}=10^{\lg \mathrm{En}}$

$\mathrm{En}=15,066 \mathrm{~J} / \mathrm{cm}^{2}$

$\mathrm{E}=4,184 . \mathrm{Cf} \cdot \mathrm{En} \cdot\left(\frac{t}{0,2}\right) \cdot\left(\frac{610^{x}}{D^{x}}\right)$

$\mathrm{E}=4,184.1 .15,066 \cdot\left(\frac{1,94}{0,2}\right) \cdot\left(\frac{610^{0,973}}{914,4^{0,973}}\right)$

$\mathrm{E}=4,184.15,066.9,7.0,675$

$\mathrm{E}=412,729 \mathrm{~J} / \mathrm{cm}^{2}$

$\mathrm{E}=412,729 \mathrm{~J} / \mathrm{cm}^{2} \cdot 0,24=99,05 \mathrm{cal} / \mathrm{cm}^{2}$

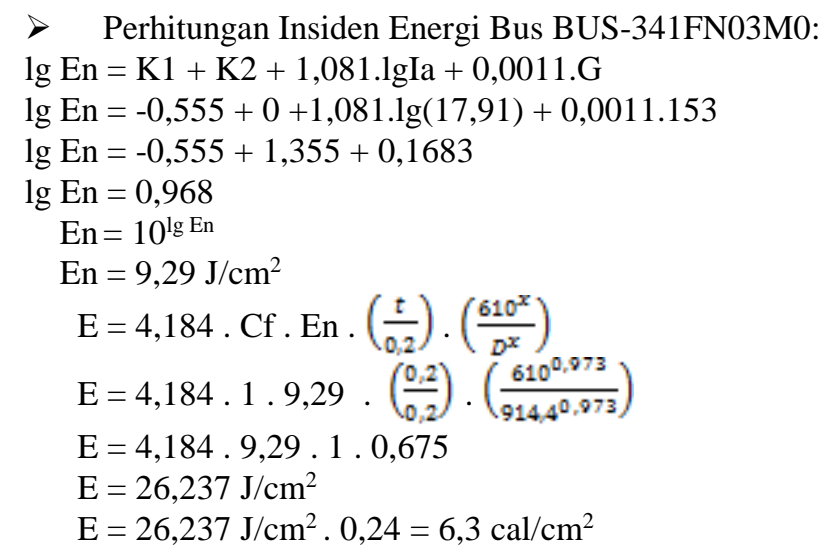

Dari hasil perhitungan manual didapatkan hasil yang hampir sama dengan hasil simulasi. Hal ini menunjukkan bahwa besaran energi yang didapat telah sesuai.

D. Perbandingan Energi Busur Api (Existing) dan (Resetting) dengan Standar IEEE 1584-2002

Tabel 5.

Hasil Perbandingan Insiden Energi Existing dan Resetting Tipikal 1

\begin{tabular}{|c|c|c|c|c|}
\hline Bus ID & $\begin{array}{c}\text { Insiden } \\
\text { Energi } \\
\text { Existing } \\
\left(\mathrm{cal}^{2} \mathrm{~cm}^{2}\right)\end{array}$ & Kategori & $\begin{array}{c}\text { Insiden } \\
\text { Energi } \\
\text { Resetting } \\
(\text { cal/cm²) }\end{array}$ & Kategori \\
\hline $821 \mathrm{MV} 011$ & 39.87 & Level 4 & 29.9 & Level 4 \\
\hline 831MV041 & 18.41 & Level 3 & 13.15 & Level 3 \\
\hline Bus30 & 98.54 & > Level 4 & 98.54 & $>$ Level 4 \\
\hline $\begin{array}{l}\text { BUS- } \\
\text { 341FN03M01 }\end{array}$ & 12.53 & Level 3 & 6.26 & Level 2 \\
\hline
\end{tabular}

Dari tabel 5 ditampilkan data besar insiden energi dan kategori level pada waktu existing dan setelah resetting untuk perhitungan dengan standar IEEE 1584-2002. Tabel tersebut menunjukkan nilai insiden energi pada kondisi resetting lebih kecil dibandingkan pada waktu existing. Pada waktu existing koordinasi proteksi dari beban menuju sumber untuk pemutusan CB tidak urut dan memiliki waktu yang lebih lama karena rele pengaman disetting awal $0.3 \mathrm{~s}$, sehingga nilai insiden energi menjadi besar. Sedangkan untuk kondisi reseeting rele pengaman sudah terkordinasi dengan benar 
dengan waktu pemutusan awal $0.1 \mathrm{~s}$, sehingga waktu untuk melokalisir gangguan semakin cepat. Semakin cepat rele dapat melokalisir gangguan maka semakin kecil nilai insiden energinya.

\section{E. Perbandingan Besar Energi Busur Api Setelah Penambahan Rele Differensial}

Salah satu yang mempengaruhi besar insiden busur api adalah waktu yang diperlukan untuk melokalisir gangguan. Dalam hal ini, rele differensial mempunyai waktu kerja yang sangat cepat, yaitu antara 1-3 cycle. Maka, setelah diberi penambahan rele differensial, besar nilai insiden energi busur api dapat dilihat pada tabel 6 .

Tabel 6.

Hasil Perbandingan Insiden Energi Existing dan Resetting Tipikal 1

\begin{tabular}{|c|c|c|c|c|}
\hline Bus ID & $\begin{array}{c}\text { Insiden } \\
\text { Energi } \\
\text { Resetting } \\
\left(\mathrm{cal}_{\mathbf{c}} \mathrm{cm}^{2}\right) \\
\end{array}$ & Kategori & $\begin{array}{c}\text { Insiden } \\
\text { Energi } \\
\text { Differensial } \\
\left(\mathbf{c a l} / \mathrm{cm}^{2}\right) \\
\end{array}$ & Kategori \\
\hline 821MV011 & 29.9 & Level 4 & 29.9 & Level 4 \\
\hline 831MV041 & 13.15 & Level 3 & 13.15 & Level 3 \\
\hline Bus30 & 98.54 & $\begin{array}{r}>\text { Level } \\
4\end{array}$ & 8.13 & Level 3 \\
\hline $\begin{array}{l}\text { BUS- } \\
\text { 341FN03M01 }\end{array}$ & 6.26 & Level 2 & 6.26 & Level 2 \\
\hline
\end{tabular}

\section{KESIMPULAN}

Berdasarkan hasil studi koordinasi proteksi dan busur api pada sistem kelistrikan di PT. Semen Indonesia pabrik Aceh, maka dapat diambil beberapa kesimpulan sebagai berikut :

1. Resetting dilakukan dengan menyesuaikan grading time rele pengaman berdasarkan koordinasi proteksi menyebabkan insiden energi yang ada semakin kecil, karena pada kondisi existing waktu pemutusan pada rele pertama terlalu besar sehingga menyebabkan nilai insiden energi menjadi besar.

2. Resetting dengan penambahan rele differensial dilakukan karena pada bus masing-masing tipikal masih terdapat nilai insiden energi yang melebihi batas yang diizinkan oleh NFPA 70E, sehingga diperlukan rele differensial untuk mempercepat waktu pemutusan gangguan sehingga nilai insiden energi menjadi kecil.

3. Rele differensial menjadi pengaman utama, sedangkan rele arus lebih menjadi pengaman back up dari rele differensial.

\section{DAFTAR PUSTAKA}

[1] NFPA 70E-2004, Electrical Safety Requirements for Employee Workplaces.

[2] IEEE Std 1584-2002 IEEE Guide for Performing Arc-Flash Hazard Calculation.

[3] Gurevich, Vladimir, "Electric Relays, Principle and Aplication”, CRCPress, USA, Ch. 10, 200. 